Draft: 9-26-01

\title{
Taxation of Financial Services under a VAT
}

\author{
Alan J. Auerbach and Roger H. Gordon*
}

In simple economic models, it is relatively easy to describe how to impose a value-added tax at a uniform rate on all consumption goods, and to demonstrate that this tax is equivalent to a proportional labor income tax, plus a tax on existing assets. The equivalence involves little more than the national income identity relating the sources and uses of income. Once one attempts to incorporate the costs of financial intermediation, however, tax analysis becomes more complicated.

In attempting to determine how a VAT should treat financial transactions, various authors have attempted to apply results from simpler models. Unfortunately, these results can lead to conflicting, ambiguous, and misleading prescriptions. In this paper, we argue that one needs to rely more on the fundamental objectives of a VAT to decide how it should treat financial transactions. Adopting this approach, we find that, in principle, the VAT should apply to resources devoted to financial transactions in the same manner that it does in other sectors. As discussed below, there are real problems, however, in implementing such a tax on the financial sector that we do not attempt to address in this paper.

\section{Equivalence of a Labor Income Tax and a VAT}

The approach we will take to judge the appropriate treatment of financial services under a VAT is to make full use of the theoretical equivalence between a labor income tax and a proportional value-added tax. We begin with an individual's lifetime budget constraint under a constant labor income tax:

$$
(1-\tau) \sum_{t}(1+r)^{-t} w_{t} h_{t}+A=\sum_{i, t}(1+r)^{-t} p_{i t} C_{i t}
$$

where $A$ is the individual's initial assets, $\tau$ is the labor income tax rate, $r$ is the real discount rate, $w_{t}$ is the nominal wage, $p_{i t}$ is the price of good $i, C_{i t}$ is consumption of good $i$, and $h_{t}$ is hours of work at date $t$. To simplify the analysis, we will assume, at first, that initial assets are zero. The resulting budget constraint,

$$
(1-\tau) \sum_{t}(1+r)^{-t} w_{t} h_{t}=\sum_{i, t}(1+r)^{-t} p_{i t} C_{i t}
$$


is then equivalent to the budget constraint with a proportional VAT at rate $s$,

$$
\sum_{t}(1+r)^{-t} w_{t} h_{t}=(1+s) \sum_{i, t}(1+r)^{-t} p_{i t} C_{i t}
$$

if $s=\tau /(1-\tau)$. With this value of $s$, government revenue, $R$, is the same as well, since

$$
R \equiv s \sum_{i, t}(1+r)^{-t} p_{i t} C_{i t}=\left(\frac{\tau}{1-\tau}\right)(1-\tau) \sum_{t}(1+r)^{-t} w_{t} h_{t}=\tau \sum_{t}(1+r)^{-t} w_{t} h_{t}
$$

Equation (3) has also been the setting for two recent articles rethinking the appropriate tax treatment of financial services under a VAT. To begin with, Harry Grubert and James Mackie (1999) argue that only final consumption goods should be taxed under a VAT, while intermediate goods are not subject to tax - any such tax distorts production. They then argue that financial services are an intermediate good, and not something that provides utility in and of itself, so should be exempt from tax. To preview later results, a value added tax is equivalent to a tax on the income of all primary factors that enter into the production of final consumer goods. All primary factors that enter into the production of financial services should be taxed under a VAT, as they are in all other sectors.

In another recent paper rethinking the appropriate tax treatment of financial services under a VAT, William Jack (1999) argues that the prices of all consumer goods should increase by the same percent under a VAT. However, he then argues that the costs of financial services could well increase by this percent even without a direct tax on this sector. In particular, prices of other goods are now higher by this percent, due to the VAT, and the cost of financial services would plausibly be proportional to the size of nominal transactions. If so, then neutrality requires no direct taxation of financial services. ${ }^{1}$

Again to preview later results, this argument does not explain why the cost of financial services might be proportional to the size of nominal transactions. It implicitly ignores the presence of real inputs used in the production of financial services. If a labor income tax in fact is equivalent to a VAT, then use of these inputs should not change when one tax is replaced by the other tax. But if these costs are left unchanged by taxation, then to that extent the price of financial services cannot have increased in proportion to the VAT under competitive conditions. 
In short, we will find that the traditional presumption under a VAT, that all primary inputs that enter into the production of a good should be taxed, is correct even for financial services. To show this convincingly, however, we add to this model an explicit treatment of the costs of financial transactions. Consider first the equilibrium under a labor-income tax. Let the consumer price for each good consist of two parts: $p_{i t}=c_{i t}+b_{i t}$. Here, $c_{i t}$ is the production costs of the good itself, while $b_{i t}$ captures any transactions costs of actually acquiring the good.

Consider the determinants of each of these terms. The production costs, $c_{i t}$, should depend on the prices of primary factors, the prices of intermediate goods, as well as the interest rate which is needed to calculate the per period user costs for durable inputs (capital). For simplicity, assume that labor is the only primary factor. Then, $c_{i t}=c_{i t}\left(\mathbf{q}_{t}, r, w\right)$, where $\mathbf{q}_{t}$ is the price vector of intermediate goods (including any transactions costs of purchase). ${ }^{2}$ Assuming that the nominal price level is irrelevant to the real economy, the functions $c_{i t}(\cdot)$ will be homogeneous of degree one in $\mathbf{q}_{t}$ and $w$.

What about the transactions cost, $b_{i t}$, incurred in purchasing this good? In general, the transactions costs in buying goods can take many forms. Partly, they represent time costs in shopping as well as in going to the bank to get cash. Time costs, however, do not enter into the budget constraint as written here (which includes only market transactions), so are not part of the term $b_{i t}{ }^{3}$ Partly, these transactions costs represent the real costs involved in administering transactions through a credit card or checks, as well as the real costs of maintaining bank branches and ATM machines to facilitate cash transactions. Also, if the expenditures occur in a different period than the one in which the funds were first earned, then these transactions costs can include the real resources (e.g. management fees) lost when investing these funds so that they will be available in a later period. In general, these costs depend on the same factor prices: $b_{i t}=b_{i t}\left(\mathbf{q}_{t}, r, w\right)$, since banks and investment brokerages also require intermediate goods, capital, and labor inputs. We will again assume that these nominal transactions costs are proportional to the price level, so that the functions $b_{i t}$ are homogeneous of degree one in $\mathbf{q}_{t}$ and $w$. 
It will also prove to be helpful to make explicit the government's budget constraint. For simplicity, we will treat the above individual as representative, and measure the government's budget constraint in per capita terms. Under a labor-income tax, the government's per capita budget constraint is

$$
\tau \sum_{t}(1+r)^{-t} w_{t} h_{t}=\sum_{i, t}(1+r)^{-t} p_{i t} G_{i t}
$$

where $G_{i t}$ is the amount of good $i$ purchased by the government in period $t$. We assume here that the government faces the same prices for commodities as do private agents, including both direct costs, $c$, and transaction costs, $b$, but we return to this issue below.

Consider now what happens when we shift from this labor income tax at rate $\tau$ to a value-added tax at rate $s=\tau /(1-\tau)$. One issue we sidestepped before, that we now want to deal with explicitly, is what happens to the price level. Denote the old prices by the vector $(w, \mathbf{c}, \mathbf{b})$ and the new prices by $\left(w^{*}\right.$, $\left.\mathbf{c}^{*}, \mathbf{b}^{*}\right)$, where $\mathbf{c}$ and $\mathbf{b}$ represent the vector of the two components that together equal the goods prices. If the nominal value of transactions changes, then individuals need more money holdings. The government obtains additional seignorage revenue in providing this extra money, generating an extra term in the budget constraint. ${ }^{4}$ In order to leave the issue of seignorage aside for the moment, let us assume that nominal income remains unchanged, i.e., that $(1-\tau) w=w^{*}$.

If the value-added tax is applied to the full purchase price of all goods, including the transactions cost, then the individual's budget constraint becomes

$$
\sum_{t}(1+r)^{-t} w_{t}^{*} h_{t}=(1+s) \sum_{i, t}(1+r)^{-t} p_{i t}^{*} C_{i t}=\left(\frac{1}{1-\tau}\right) \sum_{i, t}(1+r)^{-t} p_{i t}^{*} C_{i t} .
$$

It follows immediately that this replicates equation (2) if in fact the market clearing prices satisfy $\mathbf{p}^{*}=(1-$ $\tau) \mathbf{p}$, for then all relative prices are the same..$^{5}$

The key question is what happens to the equilibrium prices, $\mathbf{p}^{*}$. These prices consist of two components, direct costs and transactions costs. Since $c_{i t}^{*}=c_{i t}\left(\mathbf{q}_{t}{ }_{t}, r, w_{t}^{*}\right)=c_{i t}\left(\mathbf{q}_{t}{ }^{*}, r, w_{t}(1-\tau)\right)$, we infer that $c_{i t}^{*}=(1-\tau) c_{i t}$ if $\mathbf{q}_{t}^{*}=(1-\tau) \mathbf{q}_{t}$ and if the real interest rate, $r$, is unchanged. Similarly, we know that 
$b_{i t}^{*}=b_{i t}\left(\mathbf{q}_{t}^{*}, r, w_{t}^{*}\right)=b_{i t}\left(\mathbf{q}_{t}^{*}, r, w_{t}(1-\tau)\right)$. Again, we infer that $b_{i t}^{*}=(1-\tau) b_{i t}$ if $\mathbf{q}_{t}^{*}=(1-\tau) \mathbf{q}_{t}$ and if the interest rate is unchanged. Since $p_{i t}^{*}=c_{i t}^{*}+b_{i t}^{*}$, we also infer that $p_{i t}^{*}=(1-\tau) p_{i t}$ if $\mathbf{q}_{t}^{*}=(1-\tau) \mathbf{q}_{t}$ and if the interest rate is unchanged. But as $\mathbf{q}_{t}^{*}$ is a component of the vector of prices $\tilde{p}_{t}^{*}=\left(p_{1}^{*}, \ldots, p_{t}^{*}\right)$, we conclude that the equilibrium is indeed unchanged, at all dates, at these new prices and the old interest rate. ${ }^{6}$ Since all the pre-tax market prices (of final and intermediate goods) have fallen in proportion to (1$\tau)$, all prices must be multiplied by the tax term $(1+s)=1 /(1-\tau)$ in order to maintain the proposed equilibrium. As a result, nominal after-tax wage income and nominal consumer prices are exactly the same under a VAT as under a labor income tax.

The model therefore implies that the sales tax should apply to all transactions costs as well as all production costs. Therefore, all primary as well as intermediate inputs used in generating these transactions should be subject to the VAT. ${ }^{7}$ In some cases, these resources are employed by the same firm selling the consumption goods, e.g. GMC provides financing for the purchase of GM cars. In other cases, a separate company, e.g. Chemical Bank, will provide these services. Regardless, the primary inputs used in supplying financial services should be subject to the VAT, and taxes collected at earlier stages in production on intermediate goods should not be rebated.

It is easy to verify that the government's budget constraint remains unchanged in this case. Previously, this budget constraint was $\tau \sum_{t}(1+r)^{-t} w_{t} h_{t}=\sum_{i, t}(1+r)^{-t} p_{i t} G_{i t}$. Now it is $s \sum_{i, t}(1+r)^{-t} p_{i t}^{*} C_{i t}=\sum_{i, t}(1+r)^{-t} p_{i t}^{*} G_{i t}$. However, this new budget constraint can be rewritten as

$$
\left(\frac{\tau}{1-\tau}\right) \sum_{i, t}(1+r)^{-t}(1-\tau) p_{i t} C_{i t}=\sum_{i, t}(1+r)^{-t}(1-\tau) p_{i t} G_{i t} .
$$

Equation (6) immediately reduces to $\tau \sum_{i, t}(1+r)^{-t} p_{i t} C_{i t}=(1-\tau) \sum_{i, t}(1+r)^{-t} p_{i t} G_{i t}$. Given equation (2), we then conclude that equation (6) is identical to equation (4), so that the real budget constraint faced by the government is unchanged. 
These results are in fact entirely consistent with the claims made in Jack (1999), and in Chia and Whalley (1999). If financial services require no real resources, then all prices for financial services should be proportional to the general price level, and no further tax needs to be collected from the financial sector. Transactions "costs" can still include foregone interest, e.g. delayed payments when goods are purchased with a credit card. They can include a risk and liquidity premium, e.g. when bank deposits are liquid and risk-free even though the underlying assets are both illiquid and risky. These types of costs do not include any real inputs, and will increase in proportion to the nominal size of the transactions, holding other characteristics of the transactions constant. Our model shows that only the real resources used in the production of financial services should be part of the value-added tax base.

\section{Discussion}

While the above argument captures in a straightforward way our argument supporting the traditional view of the tax treatment of financial services under a VAT, it also buries a number of complications, some of which we now consider.

\section{A. Seignorage}

We have made a particular assumption about the new price level, that net prices fall to fully offset the value-added tax. This leaves the tax-inclusive price level and hence the demand for money balances and the government's revenue from seignorage unchanged. But suppose that a switch from labor income taxation to a VAT were associated with a rise in the price level, as would occur if the nominal wage, $w$, remained the same. Nominal money holdings would then increase by the same proportion so as to leave real money balances unchanged. The required increase in nominal money holdings would generate additional seignorage revenue for the government, and extra real costs for individuals.

While this one-time inflation tax collected through an increase in the price level implies that the new equilibrium under a VAT no longer quite equals the old one under a labor income tax, it does equal the old equilibrium when combined with the same one-time inflation tax. Could the optimal inflation tax change due to this shift from a labor income tax to the equivalent value-added tax? It might, perhaps, due 
to nominal rigidities. Whether this makes a shift to a VAT more or less attractive depends on the costs versus benefits of such an inflation tax, an issue not part of the above model.

\section{B. Transition Issues}

Also ignored in the above discussion are transition issues. By setting $A=0$ in the above model, we avoided this issue. If instead $A>0$, then a VAT is equivalent to a labor income tax only if goods purchased with these initial assets are exempt from the VAT. Implementing such a transition rule will be difficult in practice, however. If purchases from these assets are not exempted, then the shift to a VAT is linked to a windfall seizure of $s /(1+s)$ percent of initial assets. While such an expropriation may look attractive on efficiency grounds, as argued by Auerbach and Laurence Kotlikoff (1987), it may also appear inequitable and would likely generate fears of future such expropriations. This debate over transition rules, however, does not affect the appropriate tax treatment of financial services.

\section{Timing}

Another issue not yet considered is that the timing of tax payments changes when a VAT replaces a tax on labor income. Under a labor income tax, firms make payments to the government in proportion to their labor expense, whereas under a VAT they make payments in proportion to their value added. The timing of tax payments (and hence government revenues) can be very different under the two tax systems, particularly if goods purchased with initial assets, $A$, are exempt from tax.

Relative to the equilibrium under a labor income tax, therefore, firms need to save to finance their later tax payments under a VAT while the government needs to borrow to cover expenditures financed out of future tax revenue. What do these changes in timing imply for the real costs of financial intermediation?

This change in the timing of tax payments/receipts does not affect transactions costs as modeled above, where transactions costs are proportional to the amount of goods purchased. While this model of transactions costs may capture well the costs of ATM machines, transactions balances at banks, and use of credit cards, it does not capture well the costs of longer-term borrowing and lending. If there are costs, e.g. management fees, linked to borrowing and lending, then the cost of borrowing should exceed the rate 
of return to lending, the difference reflecting these intermediation costs. Denote the real resource costs per dollar of intermediation between borrowers and lenders by $d_{i t}=d_{i t}\left(\mathbf{q}_{t}, r, w\right)$.

If, under the labor income tax, firms had net savings and the government was a net borrower, then the shift to a VAT increases both firm savings and government borrowing. Intermediation costs therefore rise, and the equilibrium becomes less efficient than under a labor income tax. If instead, firms had been net borrowers under a labor income tax while the government was a net saver, then the shift to a VAT lowers intermediation costs, and the equilibrium is more efficient than under a labor income tax.

Finally, if firms and the government were both net borrowers or both net savers, then total intermediation costs do not change due to the shift to a VAT, as long as these intermediation costs are also subject to the VAT, i.e. $d_{i t}\left(\mathbf{q}_{t}, r, w\right)=(1+s) d_{i t}\left(\mathbf{q}_{t}{ }^{*}, r, w^{*}\right)$. As a result, the market clearing prices for borrowing or lending will not change either. Therefore, if the two tax rates are set so that the present value of VAT payments is the same as the present value of labor income tax payments from the government's perspective, then these present values are equal as well from the firm's perspective. That is, the firm can simply take the money it would have paid in labor income taxes and add it to its savings (use it to reduce its debt), and the resulting savings will be just sufficient to pay future VAT liabilities. In these cases, the initial equilibrium under a labor income tax is exactly replicated under a VAT.

Additional complications arise if value-added tax payments are risky, viewed ex ante. With the shift to a VAT, the government has riskier tax revenue, while firms face riskier tax payments, relative to what would arise under a labor income tax. In theory, financial intermediaries can facilitate trade between the government and firms to leave unchanged the risk each faces. At least in the simplest theoretical models, the risk characteristics in aggregate consumption (which equal those in VAT revenues) can be replicated by proportional investments in the market portfolio. If the government had previously been absorbing some of this risk through purchases of the market portfolio, it would now buy fewer shares and firms would no longer need to sell as many shares in order to replicate the net risk they absorbed under a labor income tax. To this extent, intermediation costs likely fall under a VAT. 


\section{Practical Considerations}

Even if the appropriate treatment of financial services under a VAT is clear in an abstract theoretical model, however, the actual implementation of such a tax on financial services can face many more practical problems than exist in other sectors.

The standard approach to implementing a VAT would be to impose a tax on the cash flow from transactions in real commodities, an $R$-base tax in the terminology of the Meade Committee Report (1978). Since the product sold by financial intermediaries is by definition a financial service, however, any cash-flow tax on their real inputs must instead take the form of an $R+F$-base tax that includes in its base all financial receipts and allows a deduction for all financial payments.

This approach immediately raises the issue of "overtaxation," as it would impose a tax not only on the real resources used by the financial sector, but also on the risk premiums received by intermediaries. As discussed above, spreads generated by risk premiums do not involve the use of real resources, and hence do not require the imposition of a VAT. On the other hand, a tax applied to risk premiums may, under certain assumptions about market completeness, not affect the market equilibrium. ${ }^{8}$

In addition, though, there would be many coordination and enforcement problems if part of the economy were subject to an $R$-base tax while the financial sector faced an $R+F$-base tax. For example, firms purchasing financial services should receive a credit for value-added taxes paid by financial intermediaries on services the firm purchases from them, but these financial transactions would not normally be part of an $R$-base tax. Evasion opportunities would also be rife with one side of a financial transaction facing a very different tax treatment than the other side of the transaction.

Border corrections required under a destination-based VAT will also be much harder when dealing with financial intermediaries. In theory, exports should be exempt from the VAT, whereas imports should be subject to the VAT. But when financial services are "imported," e.g. someone purchases insurance from a foreign financial intermediary, there is no feasible monitoring at the border. Evasion of tax should then be easy, since there are no obvious costs of importance for individuals when they use a foreign financial intermediary, e.g. a foreign branch of a domestic firm, when purchasing 
financial services. Of course the same pressures are now being faced for a broader set of transactions with the growth of internet and mail-order sales.

What options exist? The point of this paper is not to develop a new proposal for how to implement a VAT, only to point out what is desired in theory.

\section{References}

Auerbach, Alan J. "Retrospective Capital Gains Taxation.” American Economic Review, March 1991, $\underline{81}(1)$, pp. $167-78$.

Auerbach, Alan J. and Laurence J. Kotlikoff. Dynamic Fiscal Policy. Cambridge, UK: Cambridge University Press, 1987.

Chia, Ngee-Choon and John Whalley. “The Tax Treatment of Financial Intermediaries.” Journal of Money Credit and Banking, November 1999, 31(4), pp. 704-19.

Gordon, Roger H. “Taxation of Corporate Capital Income: Tax Revenue versus Tax Distortions.” Quarterly Journal of Economics, $\underline{100}(1)$, pp. 1-27.

Grubert, Harry and James Mackie. "Must Financial Services be Taxed Under a Consumption Tax?"

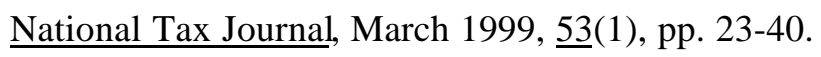

Jack, William. “The Treatment of Financial Services under a Broad-Based Consumption Tax.” National

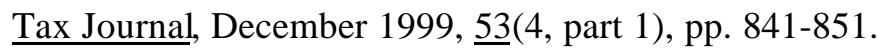

Meade, James E. et al. The Structure and Reform of Direct Taxation. London: Allen \& Unwin, 1978. 


\section{Notes}

* Auerbach: Department of Economics, University of California-Berkeley, Berkeley, CA 94720-3880;

auerbach@econ.berkeley.edu; Gordon: Department of Economics, University of California—San Diego, La Jolla, CA 92093-0508, rogordon@ucsd.edu

${ }^{1}$ Ngee-Choon Chia and John Whalley (1999) reach similar conclusions. In particular, they assume that transactions costs are proportional to nominal prices, and using simulation techniques conclude that financial services should not be taxed under a VAT.

${ }^{2}$ Note that $\mathbf{q}_{t}$ will include the prices of goods sold prior to date $t$ in the case of durable capital goods.

${ }^{3}$ If a VAT successfully replicates the equilibrium under a labor income tax, then these time costs should remain unchanged as well.

${ }^{4}$ This would represent a one-time jump in the price level, and so extra government revenue in just one period.

${ }^{5}$ Note to begin with that the assumption that $(1-\tau) w=w^{*}$ immediately implies that the left-hand sides of equations (2) and (5) are equal.

${ }^{6} \mathrm{We}$ assume that the equilibrium price vector is unique.

${ }^{7}$ As with any VAT, the tax on intermediate inputs would normally have been collected at earlier stages in production, so that the no further tax on these inputs needs to be collected at the final stage of production.

${ }^{8}$ See, for example, the discussions in Gordon (1985) and Auerbach (1991) relating, respectively, to corporate and capital gains taxation. 